\title{
Compatibilidade Vegetativa de Nit-Mutantes de Fusarium solani Patogênicos e Não-Patogênicos ao Feijoeiro e à Soja
}

\author{
Virgínia C. de Oliveira \& Jefferson L. S. da Costa \\ Embrapa Tabuleiros Costeiros, Cx. Postal 44, CEP 49001-970, Aracaju, SE, \\ fax: (079) 226-1369, e-mail: jcosta@cpatc.embrapa.br \\ (Aceito para publicação em 04/11/2002)
}

Autor para correspondência: Jefferson Luis da Silva Costa

OLIVEIRA, V.C. de, COSTA, J.L. da S. Compatibilidade vegetativa de nit- mutantes de Fusarium solani patogênicos e não-patogênicos ao feijoeiro e à soja. Fitopatologia Brasileira 28:089-092. 2003.

\section{RESUMO}

Este trabalho objetivou determinar o grau de relacionamento entre 18 isolados de Fusarium solani f. sp. phaseoli e $F$. solani $\mathrm{f}$. sp. glycines. A maioria destes isolados (14) demonstrou inespecificidade de hospedeiro sendo patogênicos ao feijoeiro (Phaseolus vulgaris) e a soja (Glycine max). Grupos de compatibilidade vegetativa de nit-mutantes destes isolados foram então determinados. Utilizou-se, como indutor de mutação, o clorato de potássio $\left(\mathrm{KClO}_{3}\right)$, sendo estes nit-mutantes justapostos sobre meio mínimo contendo $\mathrm{NANO}_{3}$ para verificar a formação de heterocariose. Dos 18 isolados de F. solani, 13 foram reunidos em um único GCV. Neste grupo os isolados nit-mutantes F42, f. sp. phaseoli e F46, f. sp. glycines, foram compatíveis entre si. Três isolados constituíram em membros únicos de GCVs diferentes, sendo um destes isolados considerado auto-incompatível. Encontrou-se, portanto, compatibilidade vegetativa entre isolados de $F$. solani $\mathrm{f}$. sp. phaseoli e $F$. solani f. sp. glycines. Esta compatibilidade pode ser uma justificativa para existência de isolados patogênicos a ambas culturas.

Palavras-chave adicionais: Phaseolus vulgaris, Glycine $\max$, relacionamento intra-específico.

\begin{abstract}
Nit-Mutant Vegetative Compatibility of Fusarium solani Pathogenic and non Pathogenic to Dry-Bean and Soybean

The purpose of this study was to determine the relatedness 18 isolates of Fusarium solani f. sp. phaseoli and F. solani f. sp. glycines. The majority of these isolates have shown host unespecificity and were pathogenic to dry-bean (Phaseolus vulgaris) and soybean (Glycine max). The vegetative compatibility groups (VCG) of these isolates were determined. The nit-mutants $\left(\mathrm{KClO}_{3}\right)$ of each isolate were paired on a $\mathrm{NANO}_{3}$ minimal media to verify the

heterocariosis formation. Among the 18 isolates of F. solani, 13 were gathered in a single VCG. The nit-mutants strains of isolate F42, f. sp. phaseoli and isolate F46, f. sp. glycines were compatible to each other. Three isolates consisted of single members of different VCGs and one of these isolates was not even incompatible with itself. Vegetative compatibility, therefore, was found among isolates of $F$. solani f. sp. phaseoli and F. solani f. sp. glycines. This compatibility could be a reason for the existence of isolates pathogenic to both crops.
\end{abstract}

O gênero Fusarium possui uma taxonomia complexa dividida em seções, formae speciales e raças. Dentro de um alto nível de especialização, forma specialis é associada a patogenicidade a apenas uma espécie hospedeira (especialização inter-específica) (Snyder \& Hansen, 1940). Esta complexidade é o principal obstáculo para a sua identificação. Este patógeno tem sido amplamente relatado no Brasil como agente causal de doenças radiculares no feijoeiro comum (Phaseolus vulgaris L.) e na soja (Glycine Max L.) (Kimati, et. al., 1997).

A podridão radicular seca do feijoeiro comum, cujo agente causal é o fungo Fusarium solani (Mart.) Hans f. sp. phaseoli, ocorre tanto na Europa como na América onde já foram constatadas reduções de até $86 \%$ na produção em situações de limitado crescimento radicular (Bianchini et. al.,
1997). Os sintomas são lesões avermelhadas no hipocótilo e raiz primária, de formato irregular, que podem coalescer com o desenvolvimento da doença, tornando-se marrons e estendendo-se até a superfície do solo. A podridão vermelha da raiz ou síndrome da morte súbita da soja, causada por $F$. solani Snyd \& Hans f. sp. glycines, foi observada pela primeira vez em Minas Gerais na safra de 1981/82 (Bianchini, et. al, 1997), e tem sido encontrada nas principais regiões produtoras de sementes do sul e das regiões altas dos cerrados (Bianchini et. al., 1997). Mancha avermelhada na raiz principal passando para negra, localizada abaixo do nível do solo, é o sintoma da doença (Bianchini, et. al, 1997).

A sustentabilidade do sistema de produção do feijoeiro em várias regiões tem exigido do produtor a necessidade de se fazer rotações entre diversas culturas. Uma das principais 


\section{V.C. Oliveira \& J.L.S. Costa}

rotações praticadas nas regiões do cerrado incluem as culturas da soja e do feijoeiro. Por este motivo, tem-se questionado se a rotação efetuada entre estas duas culturas seria adequada em solos com altos níveis de infestação com Fusarium solani.

Recentemente, várias técnicas analíticas envolvendo fisiologia e compatibilidade vegetativa têm sido utilizadas para estudar a taxonomia, filogenia e as relações patogênicas entre espécies de Fusarium (Rosalee et. al., 1999). Em genética, os testes de compatibilidade vegetativa têm sido úteis para a caracterização da diversidade entre isolados, podendo diferenciar populações patogênicas e não-patogênicas (Rosalee et. al., 1999). A obtenção de mutantes que não utilizam nitrato é utilizada para demonstrar a formação de heterocariose entre isolados compatíveis, sendo utilizada para caracterização da diversidade genética entre isolados de Fusarium sp. Puhalla (1985) modificou um método desenvolvido por Cove (1976) para testar compatibilidade vegetativa em Fusarium oxysporum (Schl.) Snyder \& Hansen utilizando mutantes que não usam nitrato (nit-). Estes estudos demonstraram que pode haver uma correlação entre a compatibilidade vegetativa (VCG) e as formae speciales. Esta compatibilidade vegetativa é mediada por múltiplos loci de incompatibilidade denominados de genes vic ou het (Leslie, 1993). Quando dois isolados de um fungo são vegetativamente compatíveis, suas hifas podem fazer contato, fusão e formação de heterocariose que, em muitos casos, ocorre quando alelos idênticos existem em cada locus vic ou het (Anagnostakis, 1982). A heterocariose ou sua reação contrária de incompatibilidade já foi observada em muitos fungos (Puhalla et. al., 1985; Leslie, 1993) incluindo F. oxysporum (Puhalla, 1985; Elmer \& Stephens, 1986) onde a fase sexual não é conhecida e a troca de material genético se dá através de mecanismos parassexuais.

Este trabalho objetivou determinar o grau de relacionamento entre 18 isolados de $F$. solani f. sp. phaseoli e $F$. solani f. sp. glycines, obtidos do feijoeiro e da soja, originários de diversas regiões brasileiras onde os sistemas de rotação incluem o feijoeiro e a soja em sequiência. Para isso, foram utilizados testes de patogenicidade e testes de compatibilidade vegetativa.

Isolados de $F$. solani foram obtidos do feijoeiro comum e da soja, originários de várias localidades (Goiânia-GO, Acreúna-GO Paranapanema-SP, Taquarituba-SP, SilvâniaGO, Santo Ântonio de Goiás-GO, Unaí-MG, Barreiras-BA, Londrina-PA e Brasília-DF), onde ambas as culturas eram integrantes do sistema de rotação. Culturas monospóricas destes isolados foram obtidas em ágar, de acordo com Booth (1977), sendo mantida em $27^{\circ} \mathrm{C}$.

Para os testes de patogenicidade, efetuaram-se inoculações cruzadas, ou seja, isolados de F. solani f. sp. glycines foram inoculados no feijoeiro e isolados de $F$. solani $\mathrm{f}$. sp. phaseoli, na soja. Para tanto, utilizou-se o método de inoculação descrito por Corrales et. al. (1987). Sementes das cultivares Rosinha (feijoeiro) e Estrela (soja) foram semeadas em vermiculita, em bandejas de plástico, em condições de casa de vegetação. Aos dez dias de idade, as plântulas foram arrancadas do solo, tiveram suas raízes cortadas a $2 \mathrm{~cm}$ de sua base e lavadas com água corrente. Posteriormente, as raízes cortadas foram imersas por $2 \mathrm{~min}$ em uma suspensão aquosa contendo $5 \times 10^{6}$ conídios/ml obtidas em meio de cultura batata-dextrose-ágar (BDA) por sete dias. Após a inoculação, as plantas foram transferidas para vasos contendo latossolo vermelho escuro previamente tratado com brometo de etila e mantidos em condições de casa de vegetação (umidade relativa do ar de $50 \%$ e temperatura de $25 \pm 2{ }^{\circ} \mathrm{C}$ ). A unidade experimental consistiu de um vaso com três plantas. Testemunhas cujas plantas, após o corte das raízes, foram imersas em água destilada também foram incluídas para comparação. Vinte e um dias após a inoculação avaliaram-se os sintomas utilizando-se uma escala de 1 a 9, sendo 1 , nenhum sintoma visível e 9, perda do sistema radicular, segundo Corrales et. al. (1987). O experimento foi disposto em um delineamento inteiramente casualizado, com três repetições, e repetido por três vezes.

Para os testes de compatibilidade vegetativa, os isolados selvagens foram cultivados em meio ágar-simples a $19^{\circ} \mathrm{C}$. Mutantes de isolados de F. solani foram desenvolvidos com o uso de um mutagênico.

Para tanto, discos de micélio (meio AS) de $9 \mathrm{~mm}$ de diâmetro foram colocados no centro de placas de Petri contendo meio batata-sucrose-ágar com 1,5\% do agente mutagênico $\mathrm{KClO}_{3}$. Os isolados que desenvolveram neste meio colônias com hifas de espessura fina e que não produziram um denso micélio aéreo foram considerados mutantes que não utilizam nitrato, conforme descrito por Puhalla (1985). Após dez dias, os nit-mutantes desenvolvidos foram transferidos para um meio mínimo à base de nitrato (MM) para efetuar o pareamento. Este meio mínimo foi preparado pela adição de $0,1 \mathrm{~g}$ de $\mathrm{NaNO}_{3}$ para 1,0 1 de meio basal (MB) e 20,0 g de ágar. O meio basal (MB), utilizado para testar a compatibilidade vegetativa foi desenvolvido por Cove (1976) e modificado por Puhalla (1985) e Correl et. al. (1987). Um dos isolados mutantes foi arbitrariamente denominado nitA; o nit-mutante que desenvolve uma linha densa de micélio em contato com a colônia central de nitA foi denominado nitB. Um disco de micélio nitA foi colocado no centro das placas de Petri com MM e pareado com outros nit-mutantes em torno do disco de micélio de nitA em todas as combinações possíveis (Puhalla, 1985). O pareamento de isolados selvagens foi utilizado como referência para auxotrofia. Os pareamentos foram incubados à $25^{\circ} \mathrm{C}$, em estufa, sob luz fluorescente, por oito dias. A interação compatível (heterocariose) se caracterizou pelo aparecimento de micélio aéreo denso na linha de contato entre duas colônias. As reações de pareamento foram observadas em microscópio estereoscópico e avaliadas por uma escala variando de 0 a 2 (Correl et. al., 1987), onde $0=$ sem reação de heterocariose; 1 = pequena reação de heterocariose com pouca formação de micélio aéreo e, 2 = reação de heterocariose com micélio aéreo abundante. Isolados vegetativamente compatíveis entre si, com notas 1 e 2 , foram considerados de um mesmo grupo de compatibilidade vegetativa. 
De acordo com os resultados do teste de patogenicidade (Tabela 1), os isolados foram divididos em três grupos: F14, F26, F36 - patogênicos apenas ao feijoeiro; F31 - patogênico apenas à soja e F1, F3, F20, F31, F33, F34, F39, F40, F41, F42, F43, F44, F45 e F46 - patogênicos a ambas as culturas. Os testes de patogenicidade não indicaram especificidade de hospedeiro, como se supõe dentro do conceito de forma specialis, tendo-se encontrado isolados de $F$. solani $\mathrm{f}$. sp. phaseoli patogênicos à soja, assim como isolados de $F$. solani f. sp. glycines também foram patogênicos ao feijoeiro. Este resultado está de acordo com Amstrong \& Armstrong (1981), no qual a especificidade de hospedeiro não ocorre para todas as formae speciales, e advoga que não deveria ser aplicado para forma specialis de Fusarium spp (apenas gênero) (Tosa, 1992). Estes mesmos autores (Armstrong \& Armstrong, 1969) verificaram que isolados de $F$. oxysporum $\mathrm{f}$. sp. raphani Ken \& Snyd. e F. oxysporum f. sp. mathioli Snyd. \& Hans. e raças de F. oxysporum f. sp. conglutinans Whell.) Snyder \& Hans., são igualmente patogênicos ao repolho (Brassica oleraceae L.) e rabanete (Raphanus sativus L.) . Em outras revisões, Armstrong \& Armstrong (1969) também verificaram que $F$. oxysporum f sp. eumartii (Carp.) Snyd \& Hans. afeta o tabaco (Nicotiana tabacum L.) e F. oxysporum f. sp. tracheiphilum (E.F. Smith) Snyd \& Hans, o crisântemo (Chrysanthemum spp.). Em trabalhos similares, Graham (1955) demonstrou que isolados de $F$. oxysporum f. sp. asparagi além de aspargos (Aspargus officinalis L.) também podem causar sintomas em gladíolo (Gladiolus spp.). Através de técnicas moleculares, O’ Donnel e Gray (1995) demonstraram, baseados na região interna espaçadora transcrita e parte da subunidade $28 \mathrm{~s}$ de rDNA, que isolados que causam a morte súbita da soja podem ser inclusos na forma especiales $F$. solani f. sp. phaseoli.

TABELA 1 - Grupos de compatibilidade vegetativa (GCV) e patogenicidade (GP) dos isolados de Fusarium solani

\begin{tabular}{lcccc}
\hline \hline Isolado & $\begin{array}{c}\text { Forma } \\
\text { specialis }\end{array}$ & Procedência & GCV & G P $^{\mathbf{y}}$ \\
\hline F1 & phaseoli & Goiânia-GO & 1 & 1 \\
F3 & phaseoli & Acreúna-GO & 1 & 1 \\
F14 & phaseoli & Silvânia-GO & 1 & 2 \\
F20 & glycines & Silvânia-GO & 1 & 1 \\
F24 & phaseoli & Unaí-MG & 1 & 1 \\
F26 & phaseoli & Unaí-MG & 1 & 2 \\
F31 & glycines & Unaí-MG & 2 & 3 \\
F33 & phaseoli & St $^{\circ}$ Antônio de GO & 1 & 1 \\
F34 & phaseoli & St $^{\circ}$ Antônio de GO & 1 & 1 \\
F36 & phaseoli & St $^{\circ}$ Antônio de GO & 1 & 2 \\
F39 & phaseoli & Silvânia-GO & 3 & 1 \\
F40 & phaseoli & Goiânia-GO & 1 & 1 \\
F41 & glycines & Paranapanema-SP & $5\left(\mathrm{~A}^{\mathrm{x}}\right)$ & 1 \\
F42 & phaseoli & Taquarituba-SP & 1 & 1 \\
F43 & glycines & Silvânia-GO & 2 & 1 \\
F44 & glycines & Barreiras-BA & 4 & 1 \\
F45 & glycines & Londrina-PR & 1 & 1 \\
F46 & glycines & Brasília-DF & 1 & 1 \\
\hline
\end{tabular}

xAuto-incompatível

${ }^{y}$ Grupos de patogenicidade: 1 = patogênico ao feijão e à soja; 2 = patogênico somente ao feijão; 3 = patogênico somente à soja.
Portanto, no presente trabalho os resultados demonstram que isolados de $F$. solani f. sp. phaseoli e $F$. solani f. sp. glycines são inespecíficos por causarem doenças no feijoeiro e na soja, independente de sua origem.

Nos testes de compatibilidade vegetativa, nit mutantes auxotróficos foram obtidos com sucesso de todos os 18 isolados de Fusarium solani. Mutantes que não utilizam nitrato podem portanto ser produzidos com o agente mutagênico $\mathrm{KClO}_{3}$ (Puhalla, 1985). Similarmente ao obtido neste trabalho, nit mutantes foram obtidos com sucesso, para caracterização da variabilidade genética em $F$. moliniforme Sheldon (Puhalla, 1985) e F. oxysporum (Elmer \& Stephens, 1986).

De acordo com os resultados obtidos (Tabela 1), treze isolados foram reunidos em um único grupo de compatibilidade vegetativa (F01, F03, F14, F20, F24, F26, F33, F34, F36, F40, F42, F45, F46). Dois isolados (F31, F43) formaram o grupo 2 de compatibilidade vegetativa. Três isolados constituíram-se membros únicos de GCVs diferentes: grupo 3, isolado F39; grupo 4, isolado F44, sendo o isolado F41 no grupo 5 inclusive autoincompatível. Isolados em um mesmo VCG são mais similares geneticamente do que isolados em diferentes grupos GCVs (Puhalla, 1985). Entretanto, os testes de compatibilidade vegetativa neste trabalho, demonstraram que isolados de $F$. solani de várias regiões pertenceram ao mesmo grupo de compatibilidade. Isto significa que, se em alguma circunstância estes isolados estivessem no mesmo hospedeiro ao mesmo tempo, a heterocariose e a complementação de alelos poderiam ocorrer (Leslie, 1993). A conseqüência disso é a ocorrência de um número menor de grupos de compatibilidade e o aumento da variabilidade genética dentro destes grupos. Este trabalho demonstrou, ainda, a formação de heterocariose entre dois isolados de formae speciales diferentes e que esta perfeita compatibilidade pode ser uma justificativa para a existência de isolados que são patogênicos a ambas culturas. Este resultado está de acordo com outras pesquisas com GCVs, nos quais estes têm sido correlacionados com patogenicidade e forma specialis ou raças (Puhalla, 1985; Elmer \& Stephens, 1986; Correl et. al., 1987). Por exemplo, Elmer \& Stephens (1986) demonstraram que o isolado MA49 identificado como F. oxysporum f. sp. asparagi não foi patogênico a plântulas de aspargo, mas formou heterocariose com todos outros membros patogênicos de um mesmo GCV. (Correl et. al., 1987) demonstraram que isolados de Fusarium oxysporum $\mathrm{f}$. sp. apii Snyd. \& Hans. raças 1 e 2 formaram um único GCV e verificou, ainda, que estes mesmos isolados foram patogênicos, também, em aspargo, e, conseqüentemente, solos em Michigan que são predominantemente infestados com uma destas raças, devem ser evitados para cultivo de aspargos. Isto se torna, portanto, um forte indicativo de que, da mesma maneira, solos infestados com $F$. solani f. sp. phaseoli e/ou $F$. solani $\mathrm{f}$. sp. glycines possam ser conducivos à doença em ambas as culturas, e que a rotação entre o feijoeiro e a soja deve ser evitada nestas áreas.

O limitado número de isolados incluídos neste estudo impede uma vasta conclusão com relação à importância da 


\section{V.C. Oliveira \& J.L.S. Costa}

formação de heterocariose na influência da diversidade genética e do fluxo gênico em $F$. solani. Porém os resultados obtidos neste trabalho destacam a necessidade de estudos adicionais acerca do número e distribuição de grupos de heterocariose na natureza. Com estas informações, poder-seá prover uma fonte de variabilidade de isolados.

Estes e outros exemplos de formação de heterocariose entre formae speciales diferentes e patogênicas à mesma cultura demonstram que, provavelmente, existam genes comuns para patogenicidade em muitas formae speciales (Armstrong \& Armstrong, 1969). A heterocariose formada por isolados geneticamente distintos de $F$. solani permitiria o contato de núcleos necessários para formação de diplóides e recombinação mitótica (Leslie, 1993), constituindo-se como um meio de variabilidade para o surgimento de novos isolados. $\mathrm{E}$, ainda, a possível interação genética entre isolados aparentemente incompatíveis pode ser resultante de mutações nos loci de incompatibilidade podendo levar à formação de subpopulações geneticamente isoladas (Leslie, 1993).

\section{REFERÊNCIAS BIBLIOGRÁFICAS}

ARMSTRONG, G.M. \& ARMSTRONG, J.K. Relationships of Fusarium oxysporum formae specialis apii, asparagi, cassiae, melongenae, and vasinfectum race 3 as revealed by pathogenicity for common hosts. Phytopathology 59:1256-1260. 1969.

ARMSTRONG, G.M. \& ARMSTRONG, J.K. Formae specilaes and races of Fusarium oxysporum causing wilt diseases. In: Nelson, PE. Toussoun, T.A. \& Cook, R.J. (Eds.) Fusarium: Disease, Biology, and Taxonomy. Pennsylvania State University Press, University Park. 1981. pp.391-399.

BIANCHINI, A., MARINGONI, A.C. \& CARNEIRO, S.M.T.P.G. Doenças do Feijoeiro. In: Kimati, H., Amorin, L., Bergamin, F.A., Camargo, L.E.A. \& Rezende, J.A. (Eds.) Manual de Fitopatologia. 3 ed. 2v. Ceres. 1997. pp.376-405.

BOOTH, C. Fusarium. Laboratory guide to the identification of the major species. Kew, Surrey, Common-wealth Mycological Institute. 1977.

CORRALES, P., ABAWI, M.A. \& ABAWI, G.S. Reactions of selected bean germoplasm to infection by Fusarium oxysporum $\mathrm{f}$. sp. phaseoli. Plant Disease 71:93. 1987. (Note)

CORREL, J.C., KLITTICHC, C.J. \& LESLIE, J.F. Nitrate nonutilizing mutants of Fusarium oxysporum and their use in vegetative compatibility tests. Phytopathology 76:1640-1646. 1987.

COVE, D.J. Chlorate toxicity in Aspergillus nidulans: The selection and characterization of chlorate resistant mutants. Hereditariety 36:191-203. 1976

ELMER, W.H. \& STEPHENS, C.T. Vegetative compatibility groupings in Fusarium oxysporum f. sp. asparagi. Phytopathology 76:1114. 1986 (Abstract).

GRAHAM, K.M. Seedling blight, a fusarial disease of asparagus. Canadian Journal of Botany 33:374-400. 1955.

KIMATI, H., AMORIM, L., BERGAMIM, F.A. \& REZENDE (Eds). Manual de Fitopatologia. Editora Agronômica Ceres LTDA. Vol. 1. 1997.

LESLIE, J.F. Fungal vegetative compatibility. Annual Review of Phytopatology 31:127-150. 1993.

O' DONNEL K. \& GRAY. E.L. Phylogenetic relationships of the soybean sudden death syndrome pathogen Fusarium solani f. sp. phaseoli inferred from rDNA sequence data and PCR primers for ITS identification. Molecular Plant-Microbe Interactions 8:709-716. 1995.

PUHALLA, J.E. Classification of strains of Fusarium oxysporum on the basis of vegetative compatibility. Canadian Journal of Botany 63:179-183. 1985.

ROSAlEE, A., COELHO, N. \& DHINGRA, O.D. Grupos de compatibilidade vegetativa entre insolados de Fusarium oxysporum não patogênicos ao feijoeiro e de $F$. oxysporum f. sp. phaseoli. Fitopatologia Brasileira 24:546-548. 1999.

SNYDER, W.C. \& HANSEN, H.N. The species concept in Fusarium. American Journal of Botany 27:64-67. 1940. 